\title{
Pelatihan, Pendamping dan Evaluasi Peningkatan Kapasitas Masyarakat di Tingkat Kelurahan dalam Mewujudkan Lorong Sehat Makassar
}

\author{
Noer Bahry Noor*, Sukri Palutturi, Syamsuddin, Rini Angraeni, Adelia U. Ady Mangilep \\ Fakultas Kesehatan Masyarakat, Universitas Hasanuddin* \\ noor_mars@yahoo.com*
}

\begin{abstract}
Abstrak
Lorong Sehat (Longset) merupakan salah satu program inovasi untuk mewujudkan perbaikan kehidupan warga sehat Kota Makassar. Program ini dikhususkan dalam meningkatkan kesadaran masyarakat agar menjaga lingkungan serta perilaku hidup bersih dan sehat, mulai dari pemberian sosialisasi sampai evaluasi program kepada warga masyarakat salah satunya yaitu untuk mengajarkan hidup sehat, mencuci tangan sebelum makan, membiasakan untuk memeriksakan bayi/balitanya ke posyandu jika ada, membuang sampah pada tempatnya dan lainnya sehingga kesehatan dasar dapat terpenuhi. Program ini juga tertuang dalam dokumen RPJMD (Rancangan Pembangunan Jangka Menengah Daerah) Kota Makassar periode 2014-2019. Pengabdian ini merupakan respon atas adanya beberapa permasalahan yang fokus permasalahannya kebanyakan didaerah pinggiran (slum area) yang dalam hal ini didominasi oleh masyarakat yang bermukim di 7000 lorong/gang Kota Makassar yang kesulitan menjangkau data dasar kesehatan. Proses perencanaan ini melibatkan masyarakat bersama pemerintahan yang dilakukan dalam sebuah pertemuan Musyawarah Perencanaan dan Pembangunan (Musrembang) dan dipantau langsung oleh pimpinan yang ada di Dinas Kesehatan, seperti kepala seksi, kepala bidang, sekretaris dinas bahkan kepala dinas yang langsung memonitoring melalui kepala puskesmas dan tokoh masyarakat tentang masalah kesehatan. Dampak yang langsung didapatkan dengan pemberdayaan masyarakat adalah warga yang ada di lorong langsung tertangani kesehatannya oleh warga yang telah diberikan pelatihan serta koordinasi langsung oleh pihak puskesmas. Berdasarkan hasil analisis pada pelatihan Lorong sehat terjadi peningkatan pengetahuan peserta mengenai Lorong sehat, Perilaku Hidup Bersih dan Sehat (PHBS), Kawasan Tanpa Rokok (KTR), personal hygiene dan Kesehatan Ibu dan Anak (KIA). Dengan adanya pelatihan Lorong Sehat ini diharapkan agar para peserta pelatihan dapat mengaplikasikan pengetahuan yang telah didapatkan dan dapat menyebarkan pengetahuannya terhadap warga di lingkungannya agar dapat membantu proses pembangunan Lorong sehat.
\end{abstract}

Kata Kunci: Pengabdian; lorong sehat; perilaku hidup bersih.

\begin{abstract}
Lorong Sehat (Longset) is one of the innovation programs to realize the improvement of the lives of healthy citizens of Makassar City. This program is specifically aimed at increasing public awareness to protect the environment and clean and healthy living behavior, from providing socialization to program evaluation to community members, one of which is to teach healthy life, wash hands before eating, get used to checking babies/toddlers to posyandu if there is, dispose of garbage in its place, and so on so that basic health can be fulfilled. This program is also contained in the Makassar City Medium-Term Development Plan (RPJMD) document for the 2014-2019 period. This service is a response to the existence of several problems that focus on the problems mostly in the periphery (slum area) which in this case is dominated by people living in 7000 aisles/alleys of Makassar City who have difficulty reaching basic health data. This planning process involves the community together with the government conducted at a Planning and Development Deliberation (Musrembang) meeting and monitored directly by leaders in the Health Office, such as section heads, field heads, official secretaries and even agency heads who directly monitor through the head of the puskesmas and figures community about health problems. The immediate impact of community empowerment was that the residents in the hallway were immediately handled by the people who had been given training and direct coordination by the puskesmas. Based on the results of the analysis on the healthy Aisle training there was an increase in participants knowledge regarding healthy aisles, Clean and Healthy Life Behavior (PHBS), NonSmoking Areas (KTR), personal hygiene and Maternal and Child Health (MCH). With the existence of this healthy Hallway training, it is expected that the trainees can apply the knowledge they have acquired and can spread their knowledge to the people in their environment so that they can help the development process of the healthy Hallway.
\end{abstract}


Keywords: Dedication; healthy aisles; clean living behavior.

\section{Pendahuluan}

Sesuai dengan visi Kota Makassar "Mewujudkan Makassar Kota Dunia Yang Nyaman Untuk Semua" dengan Misi: 1) Merekonstruksi nasib rakyat menjadi masyarakat sejahtera standar dunia, 2) Merestorasi tata ruang kota menjadi kota nyaman berkelas dunia, dan 3) Mereformasi tata pemerintahan menjadi pelayanan publik kelas dunia bebas korupsi. Maka berdasarkan misi diatas, dibuatlah masing masing visi dengan 8 program pemerintah kota, diantaranya adalah membangun lorong garden, Makassar Tidak Rantasa, BULOG (Badan Usaha Lorong) yang pada hakekatnya nantinya di gabung dalam usaha program Longset (lorong Sehat).

Lorong Sehat (Longset) mempunyai tujuan utama untuk mengubah perilaku masyarakat menjadi sehat, mulai dari pemberian sosialisasi sampai evaluasi program kepada warga masyarakat salah satunya yaitu untuk mengajarkan hidup sehat, mencuci tangan sebelum makan, membiasakan untuk memeriksakan bayi/balitanya ke posyandu jika ada, buang sampah pada tempatnya, dan lainnya sehingga kesehatan dasar dapat terpenuhi. Pengabdian ini merupakan respon atas adanya beberapa permasalahan yang fokus permasalahannya kebanyakan didaerah pinggiran (slum area) yang dalam hal ini didominasi oleh masyarakat yang bermukim di lorong-lorong Kota Makassar. Karena tingkat kepadatan penduduk di Kota Makassar masih cukup tinggi (BPS tahun 2016 sebesar 1.469.601).

Program ini juga tertuang dalam dokumen RPJMD (Rancangan Pembangunan Jangka Menengah Daerah) Kota Makassar periode 2014-2019. Inisiatif lorong karena terdapat masyarakat kota hidup di 7000 lorong/gang yang ada di Kota Makassar. Inisiatif Program Lorong Sehat (Longset) ini untuk menjangkau pendataan kesehatan dasar melalui pemberdayaan masyarakat di Kota Makassar. Mereka selaku warga Makassar hidup di lorong-lorong mempunyai kesulitan menjangkau data dasar kesehatan. Maka inisiatif memberikan dan memberdayakan masyarakat dengan melatih masyarakat dalam membantu pihak puskesmas dalam pendataan menjadi salah satu solusinya.

\section{Permasalahan Mitra}

Permasalahan yang dihadapi oleh Dinas Kesehatan Kota Makassar adalah belum tercapainya tujuan dan sasaran pembangunan khususnya di bidang pemberdayaann masyarakat dalam meningkatakan kesehatan dirinya, keluarga, dan kesehatan lingkungan yang sasaran utamanya adalah lorong-lorong yang jumlahnya kurang lebih 7000 lorong di Kota Makassar. Secara sepintas data Kota Makassar antara lain; 1) Jumlah angka harapan hidup 71,49\% yang masih rendah di Kota Makassar, 2) jumlah per1000 penduduk terdapat 2,20 Angka Kematian Kasar pada tahun 2016, 3) masih terdapatnya rumah yang belum sehat sebesar 8,55\%. Oleh sebab itu, program Lorong Sehat (Longset) ini menjadi penting di Kota Makassar, karena tingkat kepadatan penduduk di Kota Makassar tahun 2016 sebesar 1.469.601 berdasarkan Badan Pusat Statistik. Program ini juga berbasis pemberdayaan dan partisipatif masyarakat untuk mengubah perilaku dan pola pikir masyarakat tentang kesehatan.

Pencapaian indikator angka kematian bayi di Kota Makassar telah melampaui target yang telah ditetapkan, dari yang ditargetkan 6/1000 Kelahiran Hidup (KH) di tahun 2016 ternyata 
menunjukkan pencapaian yang baik dengan lebih rendahnya angka kematian bayi yaitu 2.58 per1000 kelahiran hidup (66 kematian bayi dari 25.614 kelahiran hidup). Angka ini meningkat dari tahun 2015 yaitu 1,79/1000 KH (45 kematian bayi dari 25.181 kelahiran hidup). Angka kematian bayi pada tahun 2014 yaitu 2,60/1000 KH (64 kematian bayi dari 24.590 kelahiran hidup).

Perubahan Angka Kematian Neonatal Kota Makassar pada tahun 2016 sebesar 1,44/1000 kelahiran hidup. Di Kota Makassar, AKI maternal mengalami fluktuasi selama 3 tahun terakhir yaitu pada tahun 2016 sebanyak 6 kematian ibu dari 25.614 kelahiran hidup (AKI: 23.42 / 100.000 KH) sedangkan pada 2015 sebanyak 5 kematian ibu dari 25.181 kelahiran hidup AKI: 19,86/100.000 KH). Tahun 2014 sebanyak 5 kematian ibu dari 24.590 kelahiran hidup (AKI: 20,33/100.000 KH).

Berdasarkan data yang diperoleh dari Bidang Bina Kesehatan Masyarakat status gizi balita meningkat signifikan setelah inovasi ini dilakukan, dari $2.052(2,30 \%)$ balita di tahun 2014, menurun menjadi $1.719(2,10 \%)$ di tahun 2015, dan sebesar $2.145(2,06 \%)$ di tahun 2016. Sementara untuk jumlah kasus baru gizi buruk tahun 2016 sebanyak 10 kasus dan keseluruhan tertangani.

Pada tahun 2016 jumlah persalinan yang ditolong tenaga kesehatan yaitu $26.054(95,11 \%)$ dari sejumlah 27.394 ibu bersalin. Hal jni meningkat dibandingkan tahun 2015 dimana jumlah persalinan yang ditolong tenaga kesehatan yaitu 25.240 (94,84\%) dari 26.613. Pada tahun 2014, dimana jumlah persalinan yang ditolong tenaga kesehatan sebanyak $24.621(95,11 \%)$ dari 25.886 jumlah ibu bersalin/Nifas. Peningkatan pelayanan kesehatan ini disebabkan adanya kerjasama pihak kesehatan dengan pemberdayaan masyarakat yang ada di lorong. Oleh karena itu program pengabdian ini akan senantiasa membantu program kegiatan dari Dinas Kesehatan Kota Makassar dalam mengatasi permasalahan kesehatan yang ada di Kota Makassar.

\section{Solusi yang ditawarkan}

Solusi untuk peningkatan peran serta (partisipasi) masyarakat dalam meningkatkan kesehatan mereka, pengabdian ini akan dilaksanakan dengan 3 (tiga) tahapan.

1. Tahapan pertama adalah PELATIHAN peningkatan kapasitas masyarakat di tingkat kelurahan dalam mewujudkan Lorong Sehat Kota Makassar

2. Tahapan kedua adalah PENDAMPINGAN peningkatan kapasitas masyarakat di tingkat kelurahan dalam mewujudkan Lorong Sehat Kota Makassar.

3. Tahapan ketiga adalah EVALUASI peningkatan kapasitas masyarakat di tingkat kelurahan dalam mewujudkan Lorong Sehat Kota Makassar.

\section{Target dan Luaran}

Beberapa jenis luaran yang akan dihasilkan dalam kegiatan ini adalah sebagai berikut: 
Jurnal Tepat (Teknologi Terapan Untuk Pengabdian Masyarakat), Volume 2, Nomor 1, Tahun 2019

Tabel 1. Aspek yang Menjadi Tolak Ukur dan Tindak Lanjut

\begin{tabular}{|c|c|c|c|c|c|}
\hline \multirow[b]{2}{*}{ No } & \multirow[b]{2}{*}{ Jenis Luaran } & \multicolumn{3}{|c|}{ Kategori } & \multirow{2}{*}{$\begin{array}{c}\text { Indikator } \\
\text { Pencapaian } \\
\text { Tahun } 2018 \\
\end{array}$} \\
\hline & & $\begin{array}{c}\text { Sub } \\
\text { Kategori }\end{array}$ & Wajib & Tambahan & \\
\hline 1 & $\begin{array}{l}\text { Artikel ilmiah dimuat di } \\
\text { jurnal }\end{array}$ & $\begin{array}{c}\text { Nasional } \\
\text { terakreditasi }\end{array}$ & $\sqrt{ }$ & & Submitted \\
\hline 2 & $\begin{array}{l}\text { Publikasi pada media } \\
\text { massa }\end{array}$ & Online & $\sqrt{ }$ & & Terbit \\
\hline 3 & Laporan Akhir Penelitian & & $\sqrt{ }$ & & Selesai \\
\hline 4 & $\begin{array}{l}\text { Perbaikan Tata Nilai } \\
\text { Sosial dan Kesehatan }\end{array}$ & & $\sqrt{ }$ & & $\begin{array}{l}\text { Menghasilkan warga } \\
\text { yang terlatih dalam } \\
\text { menangani kasus } \\
\text { kesehatan sederhana }\end{array}$ \\
\hline 5 & Penerapan IPTEK & & & & \\
\hline 6 & Bahan ajar & & & $\sqrt{ }$ & Draft \\
\hline
\end{tabular}

Berikut pencapaian output/luaran Program Pengabdian Kepada Masyarakat berupa Pelatihan, Pendampingan dan Evaluasi Peningkatan Kapasitas Masyarakat di Tingkat Kelurahan dalam Mewujudkan Lorong Sehat Makassar telah berjalan dengan baik. Beberapa target luaran (output) program ini telah tercapai, antara lain luaran wajib yaitu publikasi pada media massa online, perbaikan tata nilai social dan kesehatan serta penerapan IPTEK.

\section{Implementasi Kegiatan}

Progam Lorong Sehat ini tidak akan berhasil tanpa adanya partisipasi masyarakat. Karena itu pengabdian melibatkan masyarakat pada tahap perencanaan, melalui "tudang sipulung" dimana mereka mendiskusikan permasalahan di lorong seperti sanitasi, Perilaku Hidup Bersih dan Sehat (PHBS), rumah sehat, program persalinan, dll. Mengedukasi masyarakat untuk terlibat dalam kegiatan tidak merokok di dalam rumah, melalui penyediaan ruang kecil untuk merokok di lorong/gang, seperti membangun pojok rokok, sarana cuci tangan, pembuatan pot di lorong. Selain itu juga masyarakat terlibat dalam mengevaluasi pelaksanaan kegiatan agar program lorong dapat berjalan secara efektif. Memobilisasi sumberdaya melalui arisan lorong, dana yang terhimpun digunakan untuk pembinaan lorong dan pengadaan sarana melalui arisan lorong/gang.

Proses perencanaan ini juga melibatkan masyarakat bersama pemerintahan yang dilakukan dalam sebuah pertemuan Musyawarah Perencanaan dan Pembangunan (Musrembang). Musrembang ini merupakan upaya sinergisasi elemen masyarakat bersama dengan pejabat setempat melalui musyawarah demi tercapainya program lorong-lorong di Kota Makassar.

Pelaksanaan pengabdian pada lorong sehat dilakukan dalam rangka memenuhi hak-hak sipil masyarakat. Dalam upaya memenuhi hak tersebut, Pemerintah Kota Makassar membangun kemitraan dengan pihak lain untuk bersama-sama mewujudkan tujuan lorong sehat. Inisiatif ini berkaitan dengan tujuan SDGs pada tujuan sebelas yaitu Kota dan pemukiman yang berkelanjutan, tujuan tiga tentang kehidupan sehat dan sejahtera serta sarana air bersih, dan tujuan enam tentang sanitasi layak. 
Pelaksana pelatihan adalah dosen pada Fakultas Kesehatan Masyarakat Universitas Hasanuddin. Sebagai salah satu institusi pendidikan dengan salah satu fungsi pengabdian masyarakat maka dilakukan berbagai pelatihan dalam rangka meningkatkan derajat kesehatan di berbagai kalangan masyarakat. Adapun tim instruktur dalam pelatihan ini adalah dosen Fakultas Kesehatan Masyarakat Universitas Hasanuddin dengan kepakaran kedokteran, kesehatan masyarakat dan ekonomi sebagai berikut:

Tabel 2. Tim Instruktur Pelatihan

\begin{tabular}{lll}
\hline \multicolumn{1}{c}{ Jabatan } & \multicolumn{1}{c}{ Nama } & \multicolumn{1}{c}{ Bidang Kepakaran } \\
\hline Ketua & Dr. dr. Noer Bahry Noor, M.Sc & Kesehatan Masyarakat \\
Anggota & Prof. Sukri Palutturi, SKM., M.Kes., & Kesehatan Masyarakat \\
& M.Sc.PH.,Ph.D & \\
& Dr. Syamsuddin, SE., M.Si, Ak.CA & Ekonomi \\
& Rini Anggraeni, SKM,M.Kes & Kesehatan Masyarakat \\
& Adelia U. Mangilep, SKM, MARS & Kesehatan Masyarakat \\
\hline
\end{tabular}

\section{Hasil Pelaksanaan Pelatihan Lorong Sehat}

Pelatihan Lorong Sehat bagi kader dan toko masyarakat yang dilaksanakan di Fakultas Kesehatan Masyarakat ruangan K225 Fakultas Kesehatan Masyarakat Universitas Hasanuddin selama 3 hari yaitu pada tanggal 3 Oktober sampai 5 Oktober 2018. Kegiatan ini merupakan salah satu upaya untuk memberdayakan masyarakat yang bekerja sama dengan pihak kesehatan untuk mengatasi masalah kesehatan dasar.

Berikut ini distribusi peserta pelatihan Lorong sehat berdasarkan karakteristik:

Tabel 3. Distribusi Frekuensi Hasil Pre-Post Test Peserta Pelatihan Lorong Sehat Makassar Tahun 2018

\begin{tabular}{cccccc}
\hline \multirow{2}{*}{ Tingkat Pengetahuan } & \multicolumn{2}{c}{ Sebelum Pelatihan } & \multicolumn{2}{c}{ Setelah Pelatihan } \\
\cline { 2 - 5 } & $\mathbf{n}$ & $\boldsymbol{\%}$ & $\mathbf{n}$ & $\boldsymbol{\%}$ \\
\hline Baik & 16 & 53,3 & 26 & 80,0 \\
Kurang & 14 & 46,6 & 4 & 20,0 \\
\hline Total & 30 & 100 & 30 & 100 \\
\hline
\end{tabular}

Sumber: Data primer, 2018

Tabel tersebut menunjukkan bahwa terjadi peningkatan pengetahuan pada peserta pelatihan Lorong sehat pada saat sebelum pelatihan dan setelah pelatihan. Sebelum pelatihan tingkat pengetahuan hanya 16 orang $(53,3 \%)$ yang baik, dan setelah pelatihan meningkat menjadi 26 orang $(80,0 \%)$.

\section{Kesimpulan}

Program pelatihan Lorong sehat yaitu terjadi peningkatan pengetahuan peserta mengenai Lorong sehat (Longset), Perilaku Hidup Bersih dan Sehat (PHBS), Kawasan Tanpa Rokok (KTR), personal hygiene dan Kesehatan Ibu dan Anak (KIA). Dengan adanya pelatihan Lorong sehat ini diharapkan agar para peserta pelatihan dapat mengaplikasikan pengetahuan yang telah didapatkan dan dapat menyebarkan pengetahuannya terhadap warga di lingkungannya agar dapat membantu proses pembangunan Lorong sehat. 


\section{Ucapan Terima Kasih}

Terimakasih atas partisipasi masyarakat, pemerintah dan kota universitas demi terciptanya pelatihan lorong sehat di kota Makassar. Dengan adanya kegiatan ini memberikan dukungan terhadap pihak pemerintah dan dapat lebih maksimal untuk meningkatkan derajat kesehatan masyarakat di lingkungan tersebut.

\section{Daftar Pustaka}

Badan Pusat Stratistik Kota Makassar (BPS Kota Makassar). 2016. Distribusi dan Kepadatan Penduduk, Pertumbuhan Penduduk di Kota Makassar.

Peraturan Daerah Kota Makassar tentang Rencana Pembangunan Jangka Menengah Daerah (RPJMD) Kota Makassar Tahun 2014-2019.

Profil Dinas Kesehatan Kota Makassar Tahun 2015. 